\title{
INSTRUCTIONS TO CONTRIBUTORS
}

The Journal of Helminthology publishes papers on all aspects of animal parasitic helminths, particularly those of medical or veterinary importance.

Manuscripts, which must be in English or French (with an English summary), should be addressed to:

The Editor, Journal of Helminthology

London School of Hygiene and Tropical Medicine

Keppel Street, London WC1E 7HT

England

Two copies of a typescript, on size A4 paper with double spacing, should be submitted. Papers should be preceded by a short abstract and will normally have the following sections: brief introduction (unheaded); Materials and Methods; Results; Discussion; Acknowledgements; References. However, the form of the paper may vary, depending on its subject matter; recent past issues should be consulted for a suitable form. Illustrations should be drawn in Indian ink, preferably not more than double the final size. Care should be taken that all illustrations fit into the format of the Journal. The maximum size an illustration may be printed is $13.5 \times 18 \mathrm{~cm}$. Where many separate drawings are made, some indication of how they may be grouped to make a corporate plate without undue wastage of space should be indicated. Some indication of scale should normally be given on the figure. Photocopies of illustrations should also be enclosed for refereeing purposes. Lettering and numbering, which must be of a high standard, should be added by the author, with due regard for subsequent reduction.

Photographs should be glossy prints of the same size as they are to appear in the Journal (maximum size $13.5 \times 18 \mathrm{~cm}$ ). Composite prints must be mounted and can have the separate photographs abutting; they will then have a separating line inserted by the printers. All figures and letters on photographs must be inserted by the author.

Information should not be repeated in the text and in tables or figures. The legends to tables and to figures should be sufficiently detailed for the information to be understood without reference to the text.

References should be given in alphabetical order with the full title of the journal. The following are examples:

DUKE, B. O. L. (1971) The ecology of onchocerciasis in man and animals. In Ecology and physiology of parasites (ed A. M. Fallis) pp. 213-222. Adam Hilger Ltd.: London.

JAMES, C. and WEBBE, G. (1973) A comparison of Egyptian and East African strains of Schistosoma haematobium. Journal of Helminthology, 47, 49-59.

50 offprints are provided free of charge; additional copies may be ordered at the proof stage. 


\section{Journal of Helminthologiy volume $51 \bullet$ • 0.4 • doc 1977}

\section{Contents}

Pages

RAJASEKARIAH, G. R. and HOWELL, M. J. The fate of Fasciola hepatica metacercariae following challenge infection of immune rats

LIM BOO LIAT and BETTERTON, C. Paragonimus westermani in Malaysian Felidae and Viverridae: probable modes of transmission in relation to host feeding habits

MOQBEL, R. and DENHAM, D. A. Strongyloides ratti: 1. Parasitological observations on primary and secondary infections in the small intestine of rats

WASON, A. and JOHNSON, S. A new genus of hymenolepid cestodes from the Indian gerbil, Tatera indica

RUTLEDGE, T.A., SCHMIDT, G. D. and TIKASINGH, E. S. Episthmium everardisp. n. (Trematoda : Echinostomatidae) from a great kiskadee, Pitangus sulfuratus, in Trinidad

EL. BIHARI, S., HUSSEIN, H. S. and MULLER, R. Monanema nilotica n. sp. (Nematoda : Onchocercidae) a cardiopulmonary parasite of the Nile rat in Sudan

COLES, G. C. and MCNEILLIE, R. M. The response of nematodes in vivo and in vitro to some anthelmintics

PITCHFORD, R. J. and WOLSTENHOLME, R. Further observations on the relationship and distribution of Schistosoma margrebowiei and S. leiperi in central southern Africa

TAYLOR, M. G. et al. Modification of the pathogenicity of Schistosoma mattheei for sheep by passage of the parasite in hamsters

DARGIE, J. D. et al. Immunization of sheep against a virulent strain of Schistosoma mattheei using a strain of $S$. mattheei attenuated by hamster passage

RICKARD, M. D., DAVIES, C., BOUT, D. T. and SMYTH, J. D. Immunohistological localisation of two hydatid antigens (antigen 5 and antigen B) in the cyst wall, brood capsules and protoscoleces of Echinococcus granulosus (ovine and equine) and $E$. multilocularis using immunoperoxidase methods

BISSET. S. A. Notocotylus tadornae n. sp. and Notocotylus gippyensis (Beverley-Burton, 1958) (Trematoda: Notocotylidae) from waterfowl in New Zealand: morphology, life history and systematic relations

AIDER, S. A. and SIDDIQI, A. H. Alkali denaturation of oxyhaemoglobins of some digenetic trematodes and their hosts 